\title{
$\begin{array}{ll}\text { Preprints are preliminary reports that have not undergone peer review. } \\ \text { Research Square } & \text { They should not be considered conclusive, used to inform clinical practice, }\end{array}$ or referenced by the media as validated information. \\ Preparation and Test of UV Resistant and Flame Retardant Cotton Fabric With Phytic Acid, Tannic Acid and Diethylenetriamine as Raw Materials
}

\section{Xiang Zhou}

Wuhan Textile University

\section{Yankun Yin}

Wuhan Textile University

\section{Zhiyu Huang}

Wuhan Textile University

Lu Fu

Wuhan Textile University

Shaohua Chen ( $\nabla$ shaohuachen@foxmail.com )

Wuhan Textile University https://orcid.org/0000-0002-0274-2089

Hua Wang

Wuhan Textile University

\section{Luoxin Wang}

Wuhan Textile University

\section{Research Article}

Keywords: cotton fabric, phytic acid, tannic acid, anti-ultraviolet, intumescent flame retardant system, ecofriendly

Posted Date: April 19th, 2021

DOl: https://doi.org/10.21203/rs.3.rs-376887/v1

License: (c) (1) This work is licensed under a Creative Commons Attribution 4.0 International License. Read Full License 


\section{Abstract}

Although cotton fabric is widely used in various fields because of its unique advantages, it has the disadvantages of flammability and poor ultraviolet protection. By combining diethylenetriamine(DETA) $\square$ phytic acid (PA) and tannic acid(TA) on cotton fabric, a chemical reaction intumescent flame retardant cotton fabric with anti-ultraviolet and anti-flame retardant was developed. The flame retardant and ultraviolet resistance of cotton fabric were characterized by limiting oxygen index (LOI) test, vertical combustion test, cone calorimetry test and ultraviolet resistance test. Scanning electron microscopy (SEM), X-ray photoelectron spectroscopy (XPS), Fourier transform infrared spectroscopy (FT-IR) and other tests were used to analyze the chemical composition, surface morphology and residual carbon after combustion of the cotton fabric, and it was confirmed that the modified cotton fabric has good ultraviolet resistance and flame retardant performance. In this study, an eco-friendly cotton fabric treatment method was proposed, which made cotton fabric have anti-ultraviolet and flame retardant properties, and a new application of tannic acid and phytic acid in ultraviolet protection and flame retardant of fabric was put forward.

\section{Introduction}

Characterized by great comfort, air permeability, hygroscopicity and tenderness, the cotton fabrics, which have an affinity for human skin, are widely used in clothes, decoration, technical fabrics and packaging(zhang et al. 2021; Sittinun et al.2021; Li et al.2020). Due to its rapid combustion, the cotton fabrics are very dangerous while burning. Fire disasters caused by them have posed serious threats to the life and property security of humanity(Li et al.2020;Nabipour et al.2020;Guo et al.2020;Li et al.2019; Taherkhani et al.2018;Cheng et al.2020). What's more, compared to synthetic textiles, the cotton textiles have a poorer protection capacity against ultraviolet rays, and the UV protection factors of them are often lower than 15(Kan et al.2014). Appropriate exposure to sunshine is favorable for health while inappropriate exposure to sun may do some harm to human body. According to different wave length, the UV radiation is divided into three types: UVA,UVB and UVC. Usually, the ultraviolet rays and the main part of the high energy ultraviolet from the sun will be absorbed by ozone layer. UVA and UVB, which have high energy and could penetrate deeply into dermis, are the two main ultraviolet rays that could reach the ground. Long-time exposure to ultraviolet rays will accelerate the skin aging of humanity, causing premature wrinkles(Kappes et al.2006;Choi et al.2010ロHonig et al.2018). And it will increase melanin and lead to various kinds of skin diseases and skin cancers. Presently, however, there are only few researches of modification that enable cotton textiles to have great fame retardation and UV resistance, most could only have one capacity. It is rarely reported that cotton fabric has flame retardancy and UV resistance at the same time. Therefore, it has become an important issue that how to empower flame retardation and UV resistance to cotton textiles.

But in the past few decades, The most common and widely used productive method is to use fire retardant that is based on halogen and includes methanal to make cotton textiles that have the capacity of flame retardation(Zheng et al.2019;Castellano et al.2019). Halogen-based flame retardants, which 
produce a large amount of harmful gases during combustion, are gradually replaced by phosphoruscontaining flame retardants(Shen et al.2013;Zhong et al.2007;Li et al.2019). In recent years, intumescent flame retardant system has attracted more and more attention because of its synergistic flame retardant. Due to the synergistic effect of its three components, namely acid source, gas source and carbon source, it shows remarkable flame retardancy(Ge et al.2012;Fang et al.2015). In this paper, chemical reaction intumescent flame retardant cotton fabric was prepared with matrix cotton fabric as carbon source, diethylenetriamine as gas source and phytic acid as acid source. In order to improve the flame retardant effect and applicability of the intumescent flame retardant system, tannic acid was added as another carbon source. After tannic acid was added, the system also enjoyed the anti-ultraviolet performance.

As an environmental friendly, nontoxic biocompatible acid, phytic acid has been put into wide application(Jiang et al. 2012). Under thermal decomposition, it could induce cotton textiles to form coke by releasing carboxylic acid, phosphoric acid and sulfuric acid(Liu et al. 2019; Cheng et al.2020). The more we add phosphorus to cotton textiles, the better is theirs flame retardation ability, and the molecular weight of $\mathrm{P}$ of phytic acid is around 28\% (C. F. Cullis et al.1992;Zhou et al.2015). Besides, according to the mechanism of flame retardation, the synergistic effect of $\mathrm{N}$ and $\mathrm{P}$ performs better in flame retardation(Gaan et al.2008).

Tannic acid, featured with special characters such as antibacterial property, inoxidizability, the ability to precipitate protein, reducing capacity and UV resistance, is a natural phenolic compound found in many plants, and most can be found in the bark and performs well in fire resistance(Baron et al.2019;Nam et al.2017; Tributsch et al.2008;Majumdar et al.2015;Ma et al.2017;Ekambaram et al.2016). While caught in fire, the acid could effectively reduce oxidizing agent and free radical and maximize the unburned solid and burned reserves, thus helping the trees survive(Tributsch et al.2008).

So, through a low-cost, simplistic, efficient and chemically stable method, we take ecologically friendly and sustainable materials like phytic acid, Tannic acid and diethylenetriamine as our raw materials to produce chemical reaction intumescent flame retardant cotton fabric that have the capacity of flame retardation and UV resistance. The phytic acid, when used alone, can not have an ideal effect in the improvement of the flame retardation of cotton textiles and is unable to guard against ultraviolet rays. However, after adding adding tannic acid and diethylenetriamine can form intumescent flame retardant system, which can improve the flame retardant performance of cotton fabric and make it have the ability of anti ultraviolet at the same time. Phytic acid, tannic acid and diethylenetriamine are grafted onto cotton fabric by chemical reaction, so the adhesion is more reliable. This article dives into the chemical structure, flame retardation capacity and UV resistant ability of modified cotton textiles as well as the relevant mechanisms.

\section{Experimental}

\subsection{Materials and Methods}




\subsubsection{Reagents and materials}

See Table 2.1 for details of reagents and materials.

\subsubsection{Preparation of Anti-ultraviolet and Flame Retardant Cotton Fabric}

The first is the preparation of aminated cotton fabric. $30 \times 8 \mathrm{~cm}^{2}$ cotton fabric was soaked in a beaker containing a mixed solution of $30 \mathrm{ml} \mathrm{N}, \mathrm{N}$-dimethylformamide (DMF) and $20 \mathrm{ml}$ epichlorohydrin, and the beaker was placed in an oil bath with a water temperature of $85^{\circ} \mathrm{C}$ to react for $1.5 \mathrm{~h}$; Then, $1.5 \mathrm{ml}$ of diethylenetriamine (DETA) was slowly dropped into a beaker, the solution was uniformly stirred, and the obtained cotton fabric was taken out after reacting for $1 \mathrm{~h}$; The cotton fabric was washed several times with ethanol, and then the cotton fabric was repeatedly washed with distilled water to wash off the organic solvent on the surface of the cotton fabric; Finally, the sample was completely dried in an air drying oven at $70{ }^{\circ} \mathrm{C}$ to obtain ammoniated cotton fabric (CF-DETA).

Ammoniated cotton fabric was added into $100 \mathrm{ml} 0.01 \mathrm{~mol} / \mathrm{L}$ tannic acid solution for $1 \mathrm{~h}$, and put into an air drying oven at $70{ }^{\circ} \mathrm{C}$ to completely dry, thus obtaining cotton fabric named CF-DETA-TA; $4 \mathrm{ml}$ of $50 \%$ phytic acid was add to $100 \mathrm{ml}$ of distilled water and stir evenly; Then, CF-DETA-TA was added into phytic acid solution, and the reaction was shaken in a shaking table for 2 hours; Finally, the cotton fabric was dried in an air drying oven at $70{ }^{\circ} \mathrm{C}$ to obtain flame retardant cotton fabric named CF-DETA-TA-PA.

In addition, the influence of different concentrations of DETA-TA-PA (DTP) on the flame retardant properties of cotton fabrics was studied. The content of DTP was reduced to $25 \%, 50 \%$, and $75 \%$ of the original, and the flame retardant cotton fabrics were prepared by the same preparation method.

\subsection{Characterization and Performance Test of Modified Cotton Fabric}

(1) Limiting oxygen index (LOI) test: LFY-606B oxygen index meter was used to check the LOI of cotton fabric and modified cotton fabric. The sample was cut to $150 \times 58 \mathrm{~mm}^{2}$ according to the standard GB/T5454-1997.

(2) Vertical combustion test: LFY-601A vertical combustion tester was used to carry out vertical combustion test on the sample. According to the standard GB/T5455-2014, the size of the tested cotton fabric is $300 \times 80 \mathrm{~mm}^{2}$, and the flame length is $40 \mathrm{~mm}$.

(3) Cone calorimetry test: The combustion performance of raw cotton fabric and modified cotton fabric was measured by cone calorimeter, and the measured heat flux was $35 \mathrm{~kW} / \mathrm{m}^{2}$. According to the standard ISO 5660-1, the size of the tested cotton fabric is $100 \times 100 \mathrm{~mm}^{2}$, and each sample should be checked twice. 
(4) Ultraviolet protection performance test: The Ultraviolet Protection Factor (UPF) of the sample was measured on the HD902C ultraviolet protection and sun protection test system, with a wavelength of $280-400 \mathrm{~nm}$ and an interval of $5 \mathrm{~nm}$.

(5) Scanning electron microscope (SEM) test: The morphology of cotton fabric, modified cotton fabric and burned cotton fabric was characterized by JEOL JSM-IT300A SEM under $15 \mathrm{kV}$ voltage.

(6) X-ray photoelectron spectroscopy (XPS): The elements on the surface of cotton fabrics and modified cotton fabrics were characterized by Thermo Scientific ESCALAB 250 Xi spectrometer with Al Ka X-ray source $(1484 \mathrm{eV}, 300 \mathrm{~W})$.

(7) Fourier Transform Infrared Spectroscopy (FT-IR): The FT-IR spectra of carbon residue in cotton fabric, modified cotton fabric and burned cotton fabric were obtained on a FTIR spectrometer (VERTEX70) equipped with ATR accessories. The FT-IR spectrum was scanned 64 times at intervals of $4.0 \mathrm{~cm}^{-1}$ in the range of $500-4,000 \mathrm{~cm}^{-1}$.

(8) Thermogravimetric (TG) test: The thermal stability of the original and treated cotton fabrics was analyzed by Pyris $1 \mathrm{TG}$ analyzer. Under nitrogen conditions, the heating rate was $20 \mathrm{k} / \mathrm{min}$ and the temperature was $20-700^{\circ} \mathrm{C}$.

(9) Mechanical properties test: The tensile strength of samples was studied by HD026PC multifunctional electronic fabric strength tester. According to standard GB/T 3923.1-2013, the size of each sample was prepared as $30 \mathrm{~cm} \times 6 \mathrm{~cm}$. One end of the sample was fixed on the clamp, and the other end naturally fell on the next sample clamp for testing. Then the tensile strength and elongation at break of paper and paperboard at room temperature were tested at a speed of $25 \mathrm{~mm} / \mathrm{min}$.

\section{Results And Discussions}

\subsection{Analysis of Flame Retardant Performance}

In order to visually show the flammability of modified cotton fabrics, LOI tests were carried out, and the results were summarized in Table 3.1. Compared with pure cotton fabric, the LOI value of modified cotton fabric is improved, which is as follows: the LOI value of unmodified cotton fabric was $16.5 \%$ (Zhang et al.2018); the flame retardant property of cotton fabric was slightly improved with the addition of DETA, and its LOI value was $20 \%$; the LOI value of CF-DETA-TA was $25 \%$, and that of CF-DETA-TA-PA was $34 \%$. The cotton fabric treated with DETA-TA-PA (DTP) can not burn in normal atmosphere, which reaches the LOI value of flame retardant standard cotton fabric (26.0\%). Through the vertical combustion test, it can be seen from Table 3.1 that the cotton fabric burns rapidly within $12 \mathrm{~s}$ after being ignited as it is, and the afterflame time and afterglow time are $12 \mathrm{~s}$ and $14 \mathrm{~s}$ respectively. The addition of DETA can improve the flame retardancy of cotton fabric, and the residual flame time and afterglow time are 10s and 10s, respectively, with burning time slightly shortened. Compared with the control sample, the flame retardancy of CF-DETA-TA is improved. Although CF-DETA-TA burns completely, the residual flame time is 
lower than the control sample, and the afterglow time is $0 \mathrm{~s}$. As can be seen from Table 3.1, the damage length of CF-DETA-TA-PA is $75 \mathrm{~mm}$ respectively, and the afterfire and afterglow time are both $0 \mathrm{~s}$, indicating that the flame can be extinguished immediately after leaving the fire source. Therefore, the samples treated with DTP have excellent flame retardancy.

The LOI values of samples at different DTP concentrations were further studied, as shown in Table 3.2. When the sample is treated with $50 \%$ DTP, the weight of cotton fabric increases by $7.30 \%$, and the LOI value of cotton fabric is $27 \%$, which is higher than the LOI value of flame retardant standard $(26.0 \%)$. In addition, with the increase of DTP concentration, the LOI value of samples treated with DTP also increased. LOI test results show that the modified cotton fabric has excellent flame retardancy.

\subsection{Cone Calorimetry Test}

Cone calorimetry test is often used to evaluate the combustion behavior of different materials under specific conditions and provide complete flame retardant characteristics(Zhang et al. 2021;Xu et al.2020), and the test results are shown in Table 3.3. Fig. 3.1 is a graph of heat release rate (HRR), total heat release (THR), total smoke production (TSP), smoke production rate (SPR), $\mathrm{COP}$ and $\mathrm{CO}_{2} \mathrm{P}$ of the sample. As can be seen from Fig. 3.1, the HRR and THR values of the modified cotton fabric are lower than those of the raw cotton fabric. As can be seen from Table 3.3, the Av-HRR value of the modified cotton fabric is reduced and the amount of carbon residue is increased, i.e. the carbon formed during combustion of the modified sample limits the transfer of combustible volatiles and heat, resulting in lower THR value. The PkHRR value of raw cotton fabric is $117.9 \mathrm{~kW} / \mathrm{m}^{2}$, while the PkHRR value of CF-DETA-TA-PA is much lower, which is $10.4 \mathrm{~kW} / \mathrm{m}^{2}$. Similarly, the TTI value of CF is $16 \mathrm{~s}$, while CF-DETA-TA-PA cannot be ignited. The results show that the flame retardancy of the modified cotton fabric is obviously improved.

Smoke intrusion is the main cause of death during fire (Giebultowicz et al.2017). As can be seen from Fig. 3.1 (c) and (d), the smoke production rate of CF-DETA-TA-PA in the first 50s is higher than that of the raw cotton fabric, but the SPR of the modified cotton fabric after 50 s is very low, and the total smoke production is much lower than that of the control sample. In other words, CF-DETA-TA-PA not only has good flame retardancy, but also has low smoke exhaust amount, which may be due to the positive influence of phosphoric acid or polyphosphoric acid generated during combustion on the pyrolysis of cellulose, resulting in early pyrolysis of cellulose. As can be seen from Fig. 3.1 (e) and (f), the COP value of the modified cotton fabric is higher, while the $\mathrm{CO}_{2} \mathrm{P}$ value is much lower than that of the control. The high COP value may be caused by incomplete combustion of coated cotton fabric, especially when phytic acid burns, phosphoric acid or polyphosphoric acid can be produced, which catalyzes cellulose to generate carbon residue, resulting in incomplete combustion of cotton fiber. The above results prove that the modified cotton fabric has not only flame retardant performance, but also smoke suppression effect.

\subsection{Analysis of Anti-UV Performance}

According to Table 3.4, the UPF value of raw cotton fabric is 11.1(Zhong et al.2007;Farouk et al.2021;Pandiyarasan et al.2017), and the UPF values of CF-DETA, CF-DETA-TA and CF-DETA-TA-PA are 
20.7, 99.2 and 131.8 respectively, which are slightly improved. The ultraviolet transmittance of CF-DETATA-PA is less than $2.32 \%$. According to AS/NZS 4455 miniclip UPF classification system, CF-DETA-TA-PA is considered to have good UV protection performance. The results show that the modified cotton fabric not only has flame retardancy, but also has a good potential application prospect in ultraviolet protection materials (Pandiyarasan et al.2017).

\subsection{Analysis of Surface Morphology}

Fig. 3.2 is a SEM image of raw cotton fabric and modified cotton fabric. The raw cotton fabric showed a smooth surface, but after grafting DETA, it was found that the concavity and convexity of the surface increased after the graft copolymerization reaction, indicating that the organic monomer was grafted into the cellulose framework, as shown in Fig. $3.2\left(b_{1}, b_{2}\right)$. As shown in Fig. $2.2\left(c_{1}, c_{2}\right)$, after covering the tannin layer, the surface of cotton fiber is rough, and the surface of CF-DETA-TA-PA is relatively smooth than that of CF-DETA-TA, but some cracks appear locally, which indicates that a layer of phytic acid is deposited on the surface of cotton fabric. The above results indicate that the coating was successfully deposited on cotton fabric (El-Shafei et al.2015;Li et al.2015).

\subsection{Analysis of X-ray Photoelectron Spectroscopy}

Fig. 3.3 is a full-range XPS image of raw cotton fabric after modification, which shows that the surface chemical composition of cotton fabric has completely changed before and after modification. Two peaks of $285.5 \mathrm{eV}$ and $532.4 \mathrm{eV}$ are shown in the spectrum, which are attributed to $\mathrm{C} 1 \mathrm{~s}$ and $01 \mathrm{~s}$, respectively. In contrast, the two peaks of CF-DETA at $402.5 \mathrm{eV}$ and $399.4 \mathrm{eV}$ correspond to N1s, which is due to the $\mathrm{N}$ element contained in DETA. Two new peaks of $191.5 \mathrm{eV}$ and $133.9 \mathrm{eV}$ appeared in CF-DETA-TA-PA, which correspond to P2s and P2p, confirming the successful grafting of DETA and phytic acid on the cotton fabric surface (Przybylak et al.2016).

Fig. 3.4 (a), (b), (c) and (d) are high resolution XPS images of C1s, 01s and N1s and P2p, respectively. In the $C 1 \mathrm{~s}$ high resolution XPS spectrum, it is divided into three carbon states at $284.5 \mathrm{eV}, 285.6 \mathrm{eV}$ and $288.1 \mathrm{eV}$, which are divided into $\mathrm{C}-\mathrm{C} / \mathrm{C}-\mathrm{H}, \mathrm{C}-\mathrm{O} / \mathrm{C}-\mathrm{N}$ and $\mathrm{C}-\mathrm{O}-\mathrm{C}$ respectively. The $01 \mathrm{~s}$ XPS spectrum and characteristic peaks are shown in Fig. $3.4 \mathrm{~b}$. The $01 \mathrm{~s}$ peak is divided into three peaks of $533.1 \mathrm{eV}, 532.6$ $\mathrm{eV}$ and $532.0 \mathrm{eV}$, which are divided into $\mathrm{C}-\mathrm{O} / \mathrm{P}-\mathrm{O}, \mathrm{C}-\mathrm{O}-\mathrm{C}$ and $\mathrm{P}=\mathrm{O}$, respectively. The $\mathrm{N} 1 \mathrm{~s}$ peak is divided into two peaks of $402.5 \mathrm{eV}$ and $399.4 \mathrm{eV}$, corresponding to $\mathrm{C}-\mathrm{N}-\mathrm{C}$ and $\mathrm{C}-\mathrm{N}$, respectively, which are consistent with the previous report.

\subsection{Analysis of FT-IR Spectra}

Fig. 3.5 is the FTIR spectra of raw cotton fabrics and modified cotton fabrics. The peak of raw cotton fabric at $3330 \mathrm{~cm}^{-1}$ is attributed to the stretching vibration of hydroxyl groups in cotton fiber, the peak at $2895 \mathrm{~cm}^{-1}$ corresponds to the stretching vibration of $\mathrm{C}-\mathrm{C}$, the peak at $2876 \mathrm{~cm}^{-1}$ corresponds to the stretching vibration of $\mathrm{C}-\mathrm{H}$, and the peaks at $1431 \mathrm{~cm}^{-1}$ and $1335 \mathrm{~cm}^{-1}$ correspond to the bending vibration of $\mathrm{CH} 2$ and $\mathrm{CH}$ on the main chain of cotton fabric, respectively, and the characteristic peak at 
$1031 \mathrm{~cm}^{-1}$ corresponds to the stretching vibration of C-O-C in cellulose. After DETA treatment, many peaks originally existing in cotton fabric were weakened: the peak formed at $1626 \mathrm{~cm}^{-1}$ corresponds to the stretching vibration of $\mathrm{C}-\mathrm{N}$, and the peak at $1261 \mathrm{~cm}^{-1}$ proves the existence of $\mathrm{N}-\mathrm{H}$ on cotton fabric. The peak at $2963 \mathrm{~cm}^{-1}$ corresponds to the stretching vibration of the phenolic hydroxyl group after the addition of tannic acid, and the peak at $869 \mathrm{~cm}^{-1}$ corresponds to the bending vibration of the benzene ring plane. In CF-DETA-TA-PA, the absorption peak at $1760 \mathrm{~cm}^{-1}$ corresponds to the stretching vibration of $\mathrm{P}=0$, and the peak at $1196 \mathrm{~cm}^{-1}$ corresponds to the stretching vibration of P-O. The change of absorption peak position and intensity indicates that some substances are loaded on the surface of cotton fabric, which is consistent with the previously reported results (El-Shafei et al.2015).

\subsection{TG Analysis}

The thermal stability and thermal oxidation stability of control samples and treated samples were evaluated by N2 TG analysis. Fig. 3.6 is a TG and DTG diagram of the sample in $\mathrm{N}_{2}$. Table 3.5区where the decomposition rate of the modified cotton fabric is lower than that of the control cotton fabric, and the carbon residues of the CF, CF-DETA, CF-DETA-TA, CF-DETA-TA-PA are $4.3 \%, 23.6 \%, 23.2 \%$, and $43.0 \%$, respectively. Phosphoric acid or polyphosphoric acid produced in the thermal degradation process of phytic acid is beneficial to the decomposition of cellulose into carbon slag, forming an insulating dense protective layer, which can prevent convection and conduction of heat and materials and reduce the decomposition temperature. The dense layer is also beneficial to increase the carbonization yield during combustion. The analysis results show that the decomposition rate of modified cotton fabric decreases obviously.

The maximum weight loss rate of the control sample at $353^{\circ} \mathrm{C}$ is $25.7 \% /{ }^{\circ} \mathrm{C}$, and about $4.3 \%$ thermally stable carbon residue is formed at $700^{\circ} \mathrm{C}$. The modified cotton fabric is still a one-step thermal degradation process, and CF-DETA and CF-DETA-TA almost show the same thermal behavior. It can be seen from the table that the decomposition temperatures of cotton fabrics treated by DETA, DETA-TA and DETA-TA-PA are $210^{\circ} \mathrm{C}, 223^{\circ} \mathrm{C}$ and $208^{\circ} \mathrm{C}$, respectively, which are significantly lower than those of control samples, indicating that flame retardants have significant influence on the decomposition behavior of products, which is beneficial to preferential decomposition and charring. Similarly, the $T_{\max }$ and $T 10 \%$ values of the treated cotton fabric are also low. In addition, the $R_{\max }$ value of all coated cotton fabrics is low, which makes the modified cotton form more carbon residue than the control cotton, thus preventing the cotton fabric from further burning and releasing flammable volatile substances, and producing less volatile substances and combustible substances in the thermal degradation process. The data show that the modified cotton fabric has better thermal stability.( Alongi et al.2013;Lessan et al.2011)

\subsection{Surface Morphology Analysis of Residual Carbon}

Fig. 3.7 is an electron micrograph of CF and CF-DETA-TA-PA before and after combustion. Untreated samples are easy to break after burning, which can not keep the original morphology, indicating that pure cotton fabric is flammable. Fig. $3.7\left(b_{1}, b_{2}\right)$ shows the morphology of modified cotton fabric after 
combustion, that the shape of the sample remains intact and the residual carbon skeleton structure still exists clearly. There are many small bubbles on the surface of the carbon residue skeleton structure of CF-DETA-TA-PA, which is due to the decomposition of phytic acid to form phosphoric acid and pyrophosphate. (Tao et al. 2021)

\subsection{Infrared Analysis of Combustion Samples}

Fig. 3.8 shows the infrared spectra of CF and CF-DETA-TA-PA after combustion. For pure cotton fabric after burning, there is a peak at $1027 \mathrm{~cm}^{-1}$, which corresponds to the stretching vibration of cotton fabric $\mathrm{C}-\mathrm{O}-\mathrm{C}$. For the treated cotton fabric burning, the peak at $1013 \mathrm{~cm}^{-1}$ corresponds to the stretching vibration of the cotton fabric C-O-C, the peak at $2929 \mathrm{~cm}^{-1}$ corresponds to the stretching vibration of the cotton fabric $C-C$, the peak at $1219 \mathrm{~cm}^{-1}$ corresponds to the stretching vibration of $P=0$, and the peak at $1614 \mathrm{~cm}^{-1}$ corresponds to the stretching vibration of $\mathrm{P}-\mathrm{O}$. The analysis results show that the treated cotton fabric can keep a more complete structure after burning.( Jiang et al.2019;Chen et al.2019)

\subsection{Analysis of Mechanical Properties}

The mechanical properties of the control sample and the treated sample were tested. Fig. 3.9 is a stressstrain graph of cotton fabric before and after modification. The tensile strength of cotton fabric treated by DETA is higher than that of the original cotton fabric, and the tensile strength increases from $24.4 \mathrm{MPa}$ to 27.1 MPa, but the elongation at break decreases. After adding tannic acid, the tensile strength of cotton fabric is $26.6 \mathrm{MPa}$, and that of CF-DETA-TA-PA is $24.0 \mathrm{MPa}$, which can be seen that the addition of phytic acid makes the tensile strength of cotton fabric decrease. Generally speaking, the tensile strength and elongation at break of cotton fabric decreased slightly after modification. (Tania et al.2020;Muzaffar et al.2021)

\section{Summary}

In this paper, a cotton fabric with anti-ultraviolet and flame retardant was prepared by grafting DETA, tannic acid and phytic acid on the surface of cotton fabric. The LOI value of unmodified cotton fabric is $16.5 \%$, while that of treated cotton fabric can reach $34 \%$, which meets the flame retardant standard of cotton fabric. TG test shows that at $700{ }^{\circ} \mathrm{C}$, the residual mass of treated cotton fabric is $43.0 \%$, while that of raw cotton fabric is $4.3 \%$. THR, PkHRR and TSP of treated cotton fabric are obviously lower than those of untreated cotton fabric, which indicates that modified cotton fabric can effectively inhibit cotton burning. The UPF value of modified cotton fabric is 131.8, and the ultraviolet transmittance is less than $2.32 \%$. The tensile strength of the treated cotton fabric has no obvious change, but the elongation at break decreases. The morphology and structure of burned cotton fabric were analyzed by SEM and FTIR, and it was found that the modified cotton fabric could keep a more complete structure after burning. Therefore, the improvement of flame retardancy and UV resistance of modified cotton fabric has broad application prospects. 


\section{Declarations}

\section{Acknowledgments[}

The authors appreciate the financial support from the Key Research and Development Plan of Hubei Province(2020BCB068).

Author contributions Conceptualization: $X Z, Y K Y, S H C$; Methodology: $X Z, Y K Y$; Investigation: $X Z \bigotimes Y K Y, Z Y$ H, LF; Formal analysis: $X Z, Y K Y$; Writing-original draft preparation: $X Z$; Writing-review and editing: $X Z$, YKY, ZYH, LF, SHC囚HW囚LXW; Funding acquisition: SHC, HW, LXW; Resources: SHC, HW, LXW; Supervision: $X Z, Y K Y, S H C$.

Funding the Key Research and Development Plan of Hubei Province (2020BCB068).

Conflict of interest The authors declare that they have no conflicts of interest to declare.

Ethical Standards This article does not contain any studieswith human participants or animals performed by any of theauthors.

\section{Informed consent None.}

\section{References}

1. Alongi J, Carletto RA, Di Blasio A, Cuttica F, Carosio F, Bosco F, et al. Intrinsic intumescent-like flame retardant properties of DNA-treated cotton fabrics. Carbohydr Polym. 2013;96:296-304. https://doi.org/10.1016/j.carbpol.2013.03.066

2. Baron G, Altomare A, Fumagalli L, Rumio C, Carini M, Vistoli G, et al. Development of a direct ESI-MS method for measuring the tannin precipitation effect of proline-rich peptides and in silico studies on the proline role in tannin-protein interactions. Fitoterapia. 2019;136: 104-163. https://doi.org/10.1016/j.fitote.2019.05.002

3. C. F. Cullis, M. M. Hirschler, R. G. Madden. Studies of the Effects of Phosphorus and its Compounds on the Combustion of Cellulose. Polym. 1992;28: 493-497. https://doi.org/10.1016/00143057(92)90123-J

4. Castellano A, Colleoni C, lacono G, Mezzi A, Plutino MR, Malucelli G, et al. Synthesis and characterization of a phosphorous/nitrogen based sol-gel coating as a novel halogen- and formaldehyde-free flame retardant finishing for cotton fabric. Polymer Degradation and Stability. 2019;162:148-159. https://doi.org/10.1016/j.polymdegradstab.2019.02.006

5. Chen T, Hong J, Peng C, Chen G, Yuan C, Xu Y, et al. Superhydrophobic and flame retardant cotton modified with DOPO and fluorine-silicon-containing crosslinked polymer. Carbohydr Polym. 2019;208:14-21. https://doi.org/10.1016/j.carbpol.2018.12.023

6. Cheng X-W, Tang R-C, Guan J-P, Zhou S-Q. An eco-friendly and effective flame retardant coating for cotton fabric based on phytic acid doped silica sol approach. Progress in Organic Coatings. 
2020;141:105-539. https://doi.org/10.1016/j.porgcoat.2020.105539

7. Choi W, Miyamura Y, Wolber R, Smuda C, Reinhold W, Liu H, et al. Regulation of human skin pigmentation in situ by repetitive UV exposure: molecular characterization of responses to UVA and/or UVB. J Invest Dermatol. 2010;130:1685-1696. https://doi:10.1038/jid.2010.5

8. Ekambaram SP, Perumal SS, Balakrishnan A. Scope of Hydrolysable Tannins as Possible Antimicrobial Agent. Phytother Res. 2016;30:1035-1045. https://doi: 10.1002/ptr.5616

9. El-Shafei A, ElShemy M, Abou-Okeil A. Eco-friendly finishing agent for cotton fabrics to improve flame retardant and antibacterial properties. Carbohydr Polym. 2015;118:83-90. https://doi.org/10.1016/j.carbpol.2014.11.007

10. Fang F, Zhang X, Meng Y, Gu Z, Bao C, Ding X, et al. Intumescent flame retardant coatings on cotton fabric of chitosan and ammonium polyphosphate via layer-by-layer assembly. Surface and Coatings Technology. 2015;262:9-14. https://doi.org/10.1016/j.surfcoat.2014.11.011

11. Farouk R, El-Kharadly EA, Elwahy AHM, Ibrahim HI, Mousa AA. Synthesis of new reactive dyes containing commercial UV-absorbers with enhanced simultaneous dyeing and anti-UV properties for cotton fabric. Journal of the Indian Chemical Society. 2021;261:34-39. https://doi.org/10.1016/j.jics.2021.100022

12. Gaan S, Sun G, Hutches K, Engelhard MH. Effect of nitrogen additives on flame retardant action of tributyl phosphate: Phosphorus-nitrogen synergism. Polymer Degradation and Stability. 2008;93: 99-108. https://doi:10.1016/j.polymdegradstab.2007.10.013

13. Ge L-L, Duan H-J, Zhang X-G, Chen C, Tang J-H, Li Z-M. Synergistic effect of ammonium polyphosphate and expandable graphite on flame-retardant properties of acrylonitrile-butadienestyrene. Journal of Applied Polymer Science. 2012;126:1337-1343. https://DOI 10.1002/app.36997

14. Giebultowicz J, Ruzycka M, Wroczynski P, Purser DA, Stec AA. Analysis of fire deaths in Poland and influence of smoke toxicity. Forensic Sci Int. 2017;277:77-87. https://doi.org/10.1016/j.forsciint.2017.05.018

15. Guo W, Wang X, Huang J, Zhou Y, Cai W, Wang J, et al. Construction of durable flame-retardant and robust superhydrophobic coatings on cotton fabrics for water-oil separation application. Chemical Engineering Journal. 2020;398:125-661. https://doi.org/10.1016/j.cej.2020.125661

16. Honig M, Plihalova L, Spichal L, Gruz J, Kadlecova A, Voller J, et al. New cytokinin derivatives possess UVA and UVB photoprotective effect on human skin cells and prevent oxidative stress. Eur J Med Chem. 2018;150:946-957. https://doi.org/10.1016/j.ejmech.2018.03.043

17. Jiang G, Qiao J, Hong F. Application of phosphoric acid and phytic acid-doped bacterial cellulose as novel proton-conducting membranes to PEMFC. International Journal of Hydrogen Energy. 2012;37:9182-9192. https://doi:10.1016/j.ijhydene.2012.02.195

18. Jiang Z, Li H, He Y, Liu Y, Dong C, Zhu P. Flame retardancy and thermal behavior of cotton fabrics based on a novel phosphorus-containing siloxane. Applied Surface Science. 2019;479:765-775. https://doi.org/10.1016/j.apsusc.2019.02.159 
19. Kan $\mathrm{CW}, \mathrm{Au} \mathrm{CH}$. Effect of biopolishing and UV absorber treatment on the UV protection properties of cotton knitted fabrics. Carbohydr Polym. 2014;101:451-456.

https://dx.doi.org/10.1016/j.carbpol.2013.09.044

20. Kappes UP, Luo D, Potter M, Schulmeister K, Runger TM. Short- and long-wave UV light (UVB and UVA) induce similar mutations in human skin cells. J Invest Dermatol. 2006;126:667-675. https://doi:10.1038/sj.jid.5700093

21. Lessan F, Montazer M, Moghadam MB. A novel durable flame-retardant cotton fabric using sodium hypophosphite, nano TiO2 and maleic acid. Thermochimica Acta. 2011;520:48-54. https://doi:10.1016/j.tca.2011.03.012

22. Li P, Liu C, Xu Y-J, Jiang Z-M, Liu Y, Zhu P. Novel and eco-friendly flame-retardant cotton fabrics with lignosulfonate and chitosan through LbL: Flame retardancy, smoke suppression and flame-retardant mechanism. Polymer Degradation and Stability. 2020;181:109-302. https://doi.org/10.1016/j.polymdegradstab.2020.109302

23. Li S, Lin X, Li Z, Ren X. Hybrid organic-inorganic hydrophobic and intumescent flame-retardant coating for cotton fabrics. Composites Communications. 2019;14:15-20. https://doi.org/10.1016/j.coco.2019.05.005

24. Li S, Lin X, Li Z, Ren X. Hybrid organic-inorganic hydrophobic and intumescent flame-retardant coating for cotton fabrics. Composites Communications. 2019;14:15-20. https://doi.org/10.1016/j.coco.2019.05.005

25. Li X, Chen H, Wang W, Liu Y, Zhao P. Synthesis of a formaldehyde-free phosphorus-nitrogen flame retardant with multiple reactive groups and its application in cotton fabrics. Polymer Degradation and Stability. 2015;120:193-202. https://doi.org/10.1016/j.polymdegradstab.2015.07.003

26. Liu Z, Shang S, Chiu K-I, Jiang S, Dai F. Fabrication of conductive and flame-retardant bifunctional cotton fabric by polymerizing pyrrole and doping phytic acid. Polymer Degradation and Stability. 2019;167:277-282. https://doi.org/10.1016/j.polymdegradstab.2019.06.029

27. Ma M, Dong S, Hussain M, Zhou W. Effects of addition of condensed tannin on the structure and properties of silk fibroin film. Polymer International. 2017;66:151-159. https://doi: 10.1002/pi.5272

28. Majumdar R, Bag BG, Ghosh P. Mimusops elengi bark extract mediated green synthesis of gold nanoparticles and study of its catalytic activity. Applied Nanoscience. 2015;6: 521-528. https://doi: 10.1007/s13204-015-0454-2

29. Muzaffar S, Abbas M, Siddiqua UH, Arshad M, Tufail A, Ahsan M, et al. Enhanced mechanical, UV protection and antimicrobial properties of cotton fabric employing nanochitosan and polyurethane based finishing. Journal of Materials Research and Technology. 2021;11:946-956. https://doi.org/10.1016/j.jmrt.2021.01.018

30. Nabipour H, Wang X, Song L, Hu Y. Graphene oxide/zeolitic imidazolate frameworks-8 coating for cotton fabrics with highly flame retardant, self-cleaning and efficient oil/water separation performances. Materials Chemistry and Physics. 2020;256:123-656.

https://doi.org/10.1016/j.matchemphys.2020.123656

Page $12 / 23$ 
31. Nam S, Condon BD, Xia Z, Nagarajan R, Hinchliffe DJ, Madison CA. Intumescent flame-retardant cotton produced by tannic acid and sodium hydroxide. Journal of Analytical and Applied Pyrolysis. 2017;126: 239-246. https://doi.org/10.1016/j.jaap.2017.06.003

32. Pandiyarasan V, Archana J, Pavithra A, Ashwin V, Navaneethan M, Hayakawa Y, et al. Hydrothermal growth of reduced graphene oxide on cotton fabric for enhanced ultraviolet protection applications. Materials Letters. 2017;188:123-126. https://doi.org/10.1016/j.matlet.2016.11.047

33. Przybylak M, Maciejewski H, Dutkiewicz A, Wesołek D, Władyka-Przybylak M. Multifunctional, strongly hydrophobic and flame-retarded cotton fabrics modified with flame retardant agents and silicon compounds. Polymer Degradation and Stability. 2016;128:55-64. https:// doi.org/10.1016/j.polymdegradstab.2016.03.003

34. Shen Z-Q, Chen L, Lin L, Deng C-L, Zhao J, Wang Y-Z. Synergistic Effect of Layered Nanofillers in Intumescent Flame-Retardant EPDM: Montmorillonite versus Layered Double Hydroxides. Industrial \& Engineering Chemistry Research. 2013;52:8454-8463. https://doi.org/10.1021/ie4010546

35. Sittinun A, Chang Y-H, Ummartyotin S. Development of geopolymer derived from slag waste based composite film on cotton fabric: A preliminary approach for flame retardant behavior. Materialia. 2021;15:10-1052. https://doi.org/10.1016/j.mtla.2021.101052

36. Taherkhani A, Hasanzadeh M. Durable flame retardant finishing of cotton fabrics with poly(amidoamine) dendrimer using citric acid. Materials Chemistry and Physics. 2018;219:425-432. https://doi.org/10.1016/j.matchemphys.2018.08.058

37. Tania IS, Ali M. Effect of the coating of zinc oxide ( $\mathrm{ZnO})$ nanoparticles with binder on the functional and mechanical properties of cotton fabric. Materials Today: Proceedings. 2020;38:2607-2611. https://doi.org/10.1016/j.matpr.2020.08.171

38. Tao Y, Liu C, Li P, Wang B, Xu Y-J, Jiang Z-M, et al. A flame-retardant PET fabric coating: Flammability, anti-dripping properties, and flame-retardant mechanism. Progress in Organic Coatings. 2021;150:105-971. https://doi.org/10.1016/j.porgcoat.2020.105971

39. Tributsch H, Fiechter S. The material strategy of fire-resistant tree barks. In: Proceedings of High Performance Structures and Materials IV. Conference, Conference 2008; 97:43-52. https://doi:10.2495/HPSM080051

40. Xu D, Gao Z, Xu B, Ren H, Zhao X, Zhang Y, et al. A facile and effective flame-retardant coating for cotton fabric with a-aminodiphosphonate siloxane. Polymer Degradation and Stability. 2020;180:109-312. https://doi.org/10.1016/j.polymdegradstab.2020.109312

41. Zhang A-N, Zhao H-B, Cheng J-B, Li M-E, Li S-L, Cao M, et al. Construction of durable eco-friendly biomass-based flame-retardant coating for cotton fabrics. Chemical Engineering Journal. 2021;410:128-361. https://doi.org/10.1016/j.cej.2020.128361

42. Zhang F, Gao W, Jia Y, Lu Y, Zhang G. A concise water-solvent synthesis of highly effective, durable, and eco-friendly flame-retardant coating on cotton fabrics. Carbohydr Polym. 2018;199:256-265. https://doi.org/10.1016/j.carbpol.2018.05.085 
43. Zheng Z, Liu Y, Dai B, Meng C, Guo Z. Fabrication of cellulose-based halogen-free flame retardant and its synergistic effect with expandable graphite in polypropylene. Carbohydr Polym. 2019;213:257-265. https://doi.org/10.1016/j.carbpol.2019.02.088

44. Zhong H, Wei P, Jiang P, Wu D, Wang G. Synthesis and characteristics of a novel silicon-containing flame retardant and its application in poly[2,2-propane-(bisphenol)carbonate]/acrylonitrile butadiene styrene. Journal of Polymer Science Part B: Polymer Physics. 2007;45:1542-1551. https://doi: 10.1002/polb.21151

45. Zhou Y, Ding C, Qian X, An X. Further improvement of flame retardancy of polyaniline-deposited paper composite through using phytic acid as dopant or co-dopant. Carbohydr Polym. 2015;115:670676. https://doi.org/10.1016/j.carbpol.2014.09.02

\section{Tables}

Table 2.1 Reagents and materials

\begin{tabular}{|llll|}
\hline Experimental materials & $\begin{array}{l}\text { chemical } \\
\text { formula }\end{array}$ & Specifications & manufactor \\
tannic acid & $\mathrm{C}_{76} \mathrm{H}_{52} \mathrm{O}_{46}$ & $\begin{array}{l}\text { Analytically } \\
\text { pure }\end{array}$ & Aladdin Industrial Corporation \\
phytic acid & $\mathrm{C}_{6} \mathrm{H}_{18} \mathrm{O}_{24} \mathrm{P}_{6}$ & $\begin{array}{l}\text { Analytically } \\
\text { pure }\end{array}$ & Aladdin Industrial Corporation \\
\hline epoxy chloropropane & $\mathrm{C}_{3} \mathrm{H}_{5} \mathrm{ClO}$ & $\begin{array}{l}\text { Analytically } \\
\text { pure }\end{array}$ & $\begin{array}{l}\text { Sinopharm Chemical ReagentCo., } \\
\text { Ltd }\end{array}$ \\
\hline $\begin{array}{l}\mathrm{N} \text {. N- } \\
\text { dimethylformamide }\end{array}$ & $\mathrm{C}_{3} \mathrm{H}_{7} \mathrm{NO}$ & $\begin{array}{l}\text { Analytically } \\
\text { pure }\end{array}$ & $\begin{array}{l}\text { Sinopharm Chemical ReagentCo., } \\
\text { Ltd }\end{array}$ \\
\hline Diethylenetriamine & $\mathrm{C}_{4} \mathrm{H}_{13} \mathrm{~N}_{3}$ & $\begin{array}{l}\text { Chemical purity } \\
\text { Sinopharm Chemical ReagentCo., } \\
\text { Ltd }\end{array}$ \\
\hline ethanol & $\mathrm{C}_{2} \mathrm{H}_{5} \mathrm{OH}$ & $\begin{array}{l}\text { Analytically } \\
\text { pure }\end{array}$ & $\begin{array}{l}\text { Sinopharm Chemical ReagentCo., } \\
\text { Ltd }\end{array}$ \\
\hline acetone & $\mathrm{CH}_{3} \mathrm{COCH}_{3}$ & $\begin{array}{l}\text { Analytically } \\
\text { pure }\end{array}$ & $\begin{array}{l}\text { Sinopharm Chemical ReagentCo., } \\
\text { Ltd }\end{array}$ \\
\hline
\end{tabular}

Table.3.1 Data from LOI and vertical burning tests of untreated samples and treated cotton fabric. 


\begin{tabular}{|c|c|c|c|c|}
\hline sample & LOI囚\%区 & Afterglow time $\ \mathbf{s} \rrbracket$ & Afterglow time $₫ s \rrbracket$ & Loss length $囚 \mathrm{~mm} \rrbracket$ \\
\hline $\mathrm{CF}$ & 16.5 & 12 & 14 & 300 \\
\hline CF-DETA & 20 & 10 & 10 & 300 \\
\hline CF-DETA-TA & 25 & 8 & 0 & 300 \\
\hline CF-DETA-TA-PA & 34 & 0 & 0 & 75 \\
\hline
\end{tabular}

Table.3.2 LOI values of samples treated with different concentrations of DTP.

\begin{tabular}{|c|c|c|}
\hline sample & Weight gain $\nabla w t \% \bigotimes$ & LOIه\%区 \\
\hline $25 \% \mathrm{DTP}$ & 3.11 & 25.5 \\
\hline $50 \% \mathrm{DTP}$ & 7.30 & 27 \\
\hline $75 \% \mathrm{DTP}$ & 12.72 & 31 \\
\hline $100 \%$ DTP & 16.72 & 34 \\
\hline
\end{tabular}

Table.3.3 Cone calorimetry results of samples.

\begin{tabular}{|lllllll|}
\hline sample & TTI(s) & PkHRR $(\mathrm{kW} / \mathrm{m} 2)$ & TTPHRR(s) & AvHRR(kW/m2) & THR(MJ/m2) & TSP(m2) \\
CF & 16 & 117.9 & 35 & 15.4 & 4.3 & 1.8 \\
$\begin{array}{l}\text { CF-DETA- } \\
\text { TA-PA }\end{array}$ & - & 10.4 & 265 & 6.0 & 1.8 & 0.6 \\
\hline
\end{tabular}

Table.3.4 UPF values of the samples

\begin{tabular}{|lllll|}
\hline II & UPF & T(UVA)\% & T(UVB)\% & T(UVR)\% \\
\hline CF & 11.1 & 11.92 & 6.77 & 10.41 \\
\hline CF-DETA & 20.7 & 5.94 & 10.53 & 7.32 \\
\hline CF-DETA-TA & 99.2 & 2.57 & 3.07 & 2.74 \\
\hline CF-DETA-TA-PA & 131.8 & 2.63 & 1.51 & 2.32 \\
\hline
\end{tabular}

Table.3.5 Data from TG and DTG curves of the control and modified cotton fabrics in $\mathrm{N}_{2}$. 


\begin{tabular}{|llllll|}
\hline Samples & $\mathrm{T}_{5 \%}\left({ }^{\circ} \mathrm{C}\right)$ & $\mathrm{T}_{10 \%}\left({ }^{\circ} \mathrm{C}\right)$ & $\mathrm{T}_{\max }\left({ }^{\circ} \mathrm{C}\right)$ & $\mathrm{R}_{\max }\left(\% /{ }^{\circ} \mathrm{C}\right)$ & Residue at $700{ }^{\circ} \mathrm{C} \otimes \%$ \\
\hline CF & 244 & 323 & 353 & 25.7 & 4.3 \\
\hline CF-DETA & 210 & 243 & 290 & 5.2 & 23.6 \\
\hline CF-DETA-TA & 223 & 247 & 289 & 4.9 & 23.2 \\
\hline CF-DETA-TA-PA & 208 & 245 & 275 & 10.6 & 43.0 \\
\hline
\end{tabular}

\section{Figures}

(a)

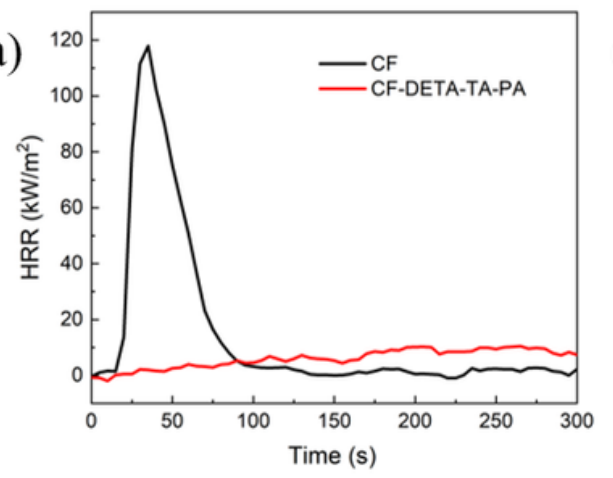

(d)

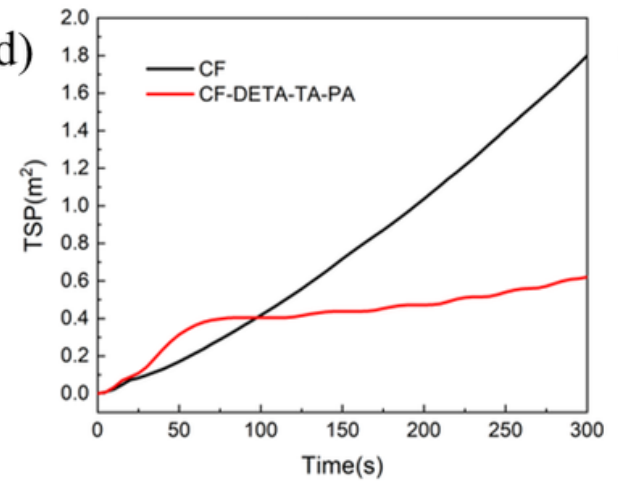

(b)

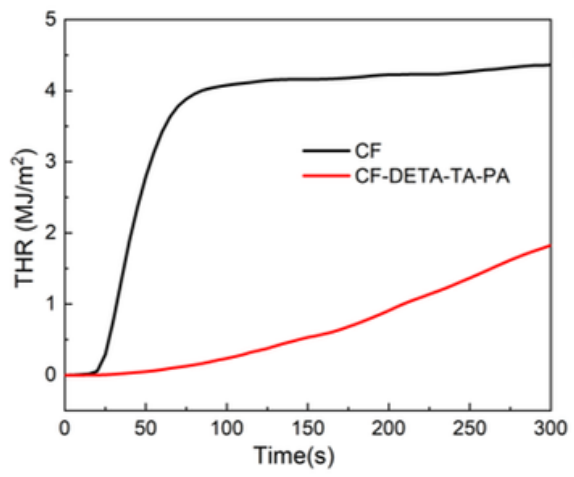

(e)

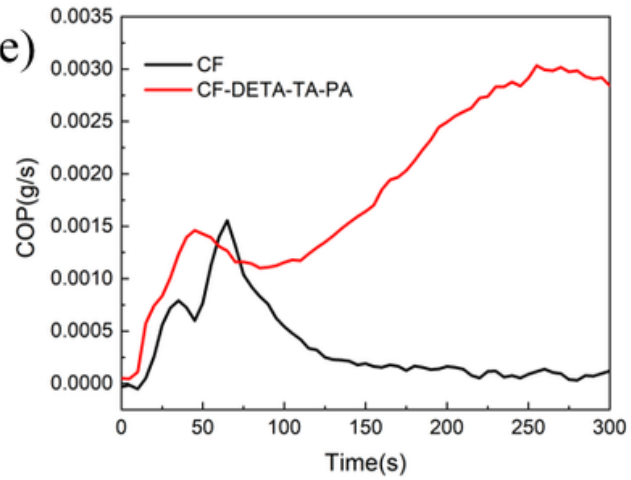

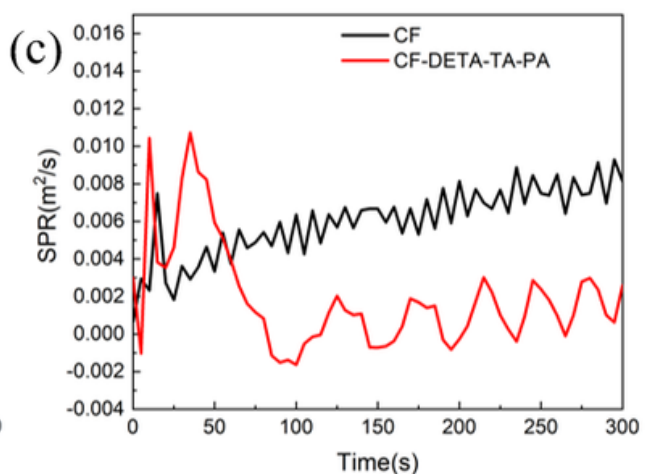

(f)

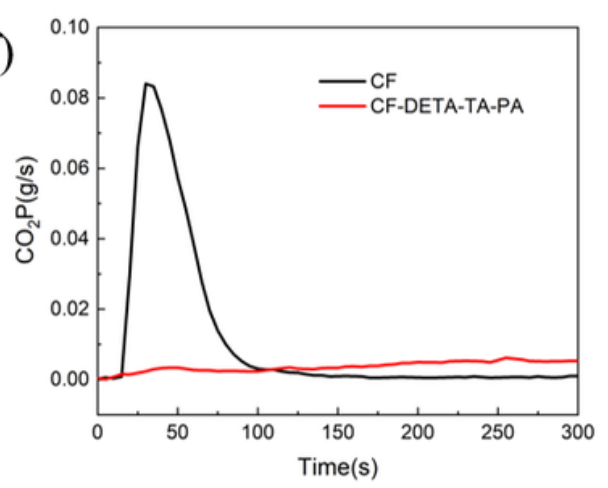

Figure 1

3.1 HRR (a), THR (b), SPR (c), TSP (d), COP (e) and CO2P (f) curves of samples. 

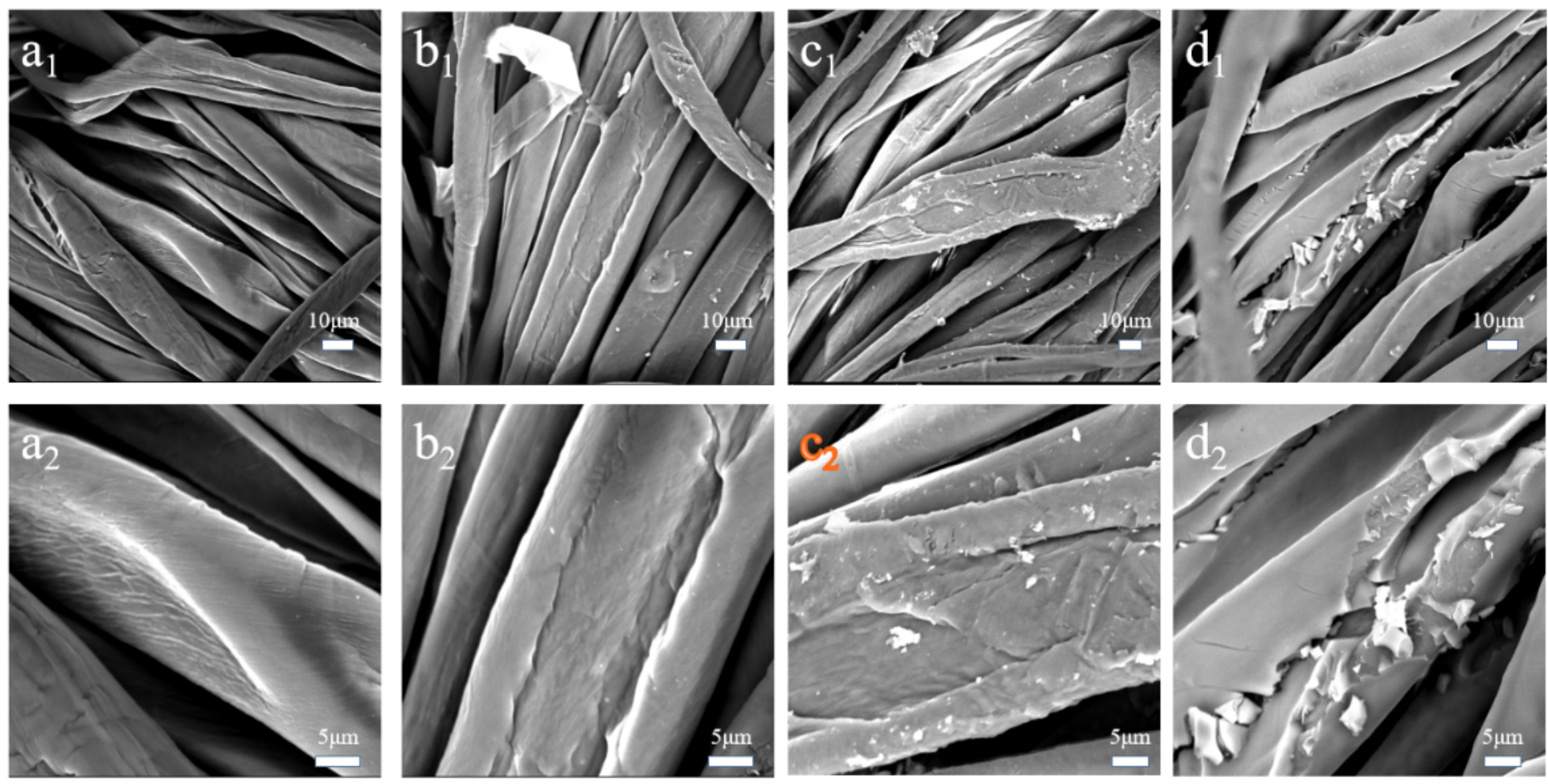

Figure 2

3.2 SEM images of (a1, a2) CF, (b1, b2 ) CF-DETA , (c1,c2) CF-DETA-TA and(d1,d2) CF-DETA-TA-PA. 


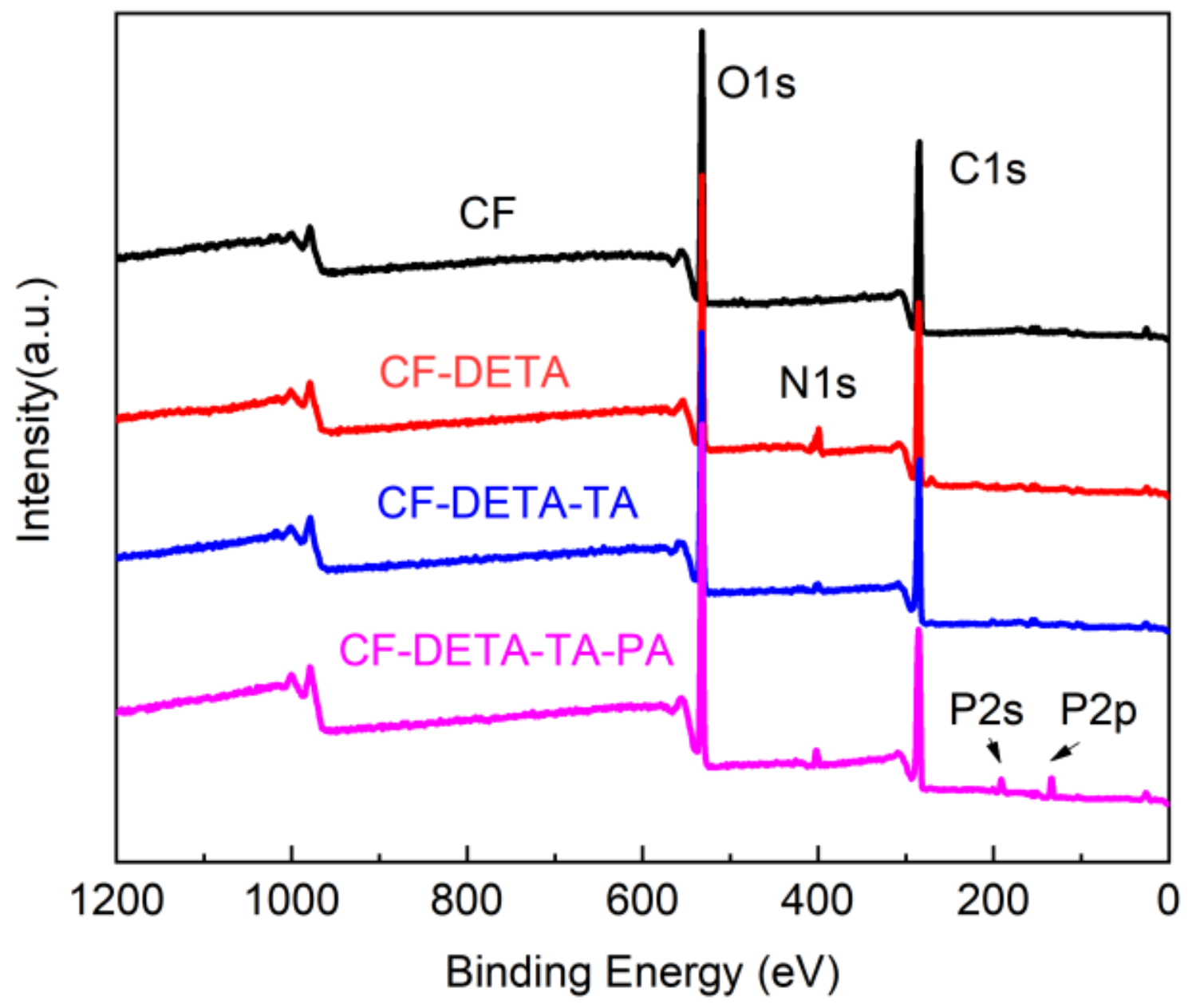

Figure 3

3.3 XPS survey spectra of pristine cotton fabric and modified cotton fabrics. 

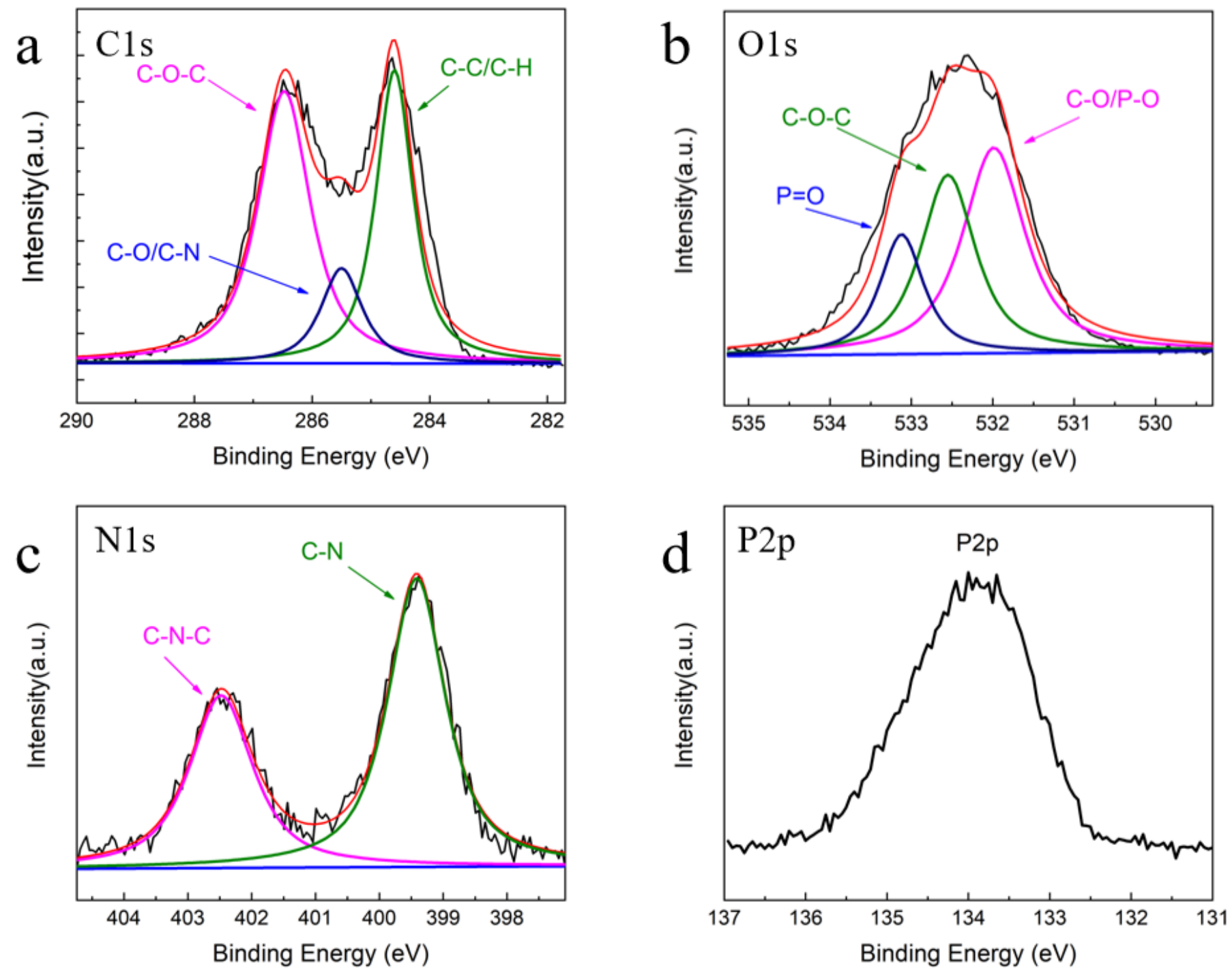

Figure 4

3.4(a) C 1s, (b) 0 1s, (c) N1s and P2p spectra of CF-DETA-TA-PA. 


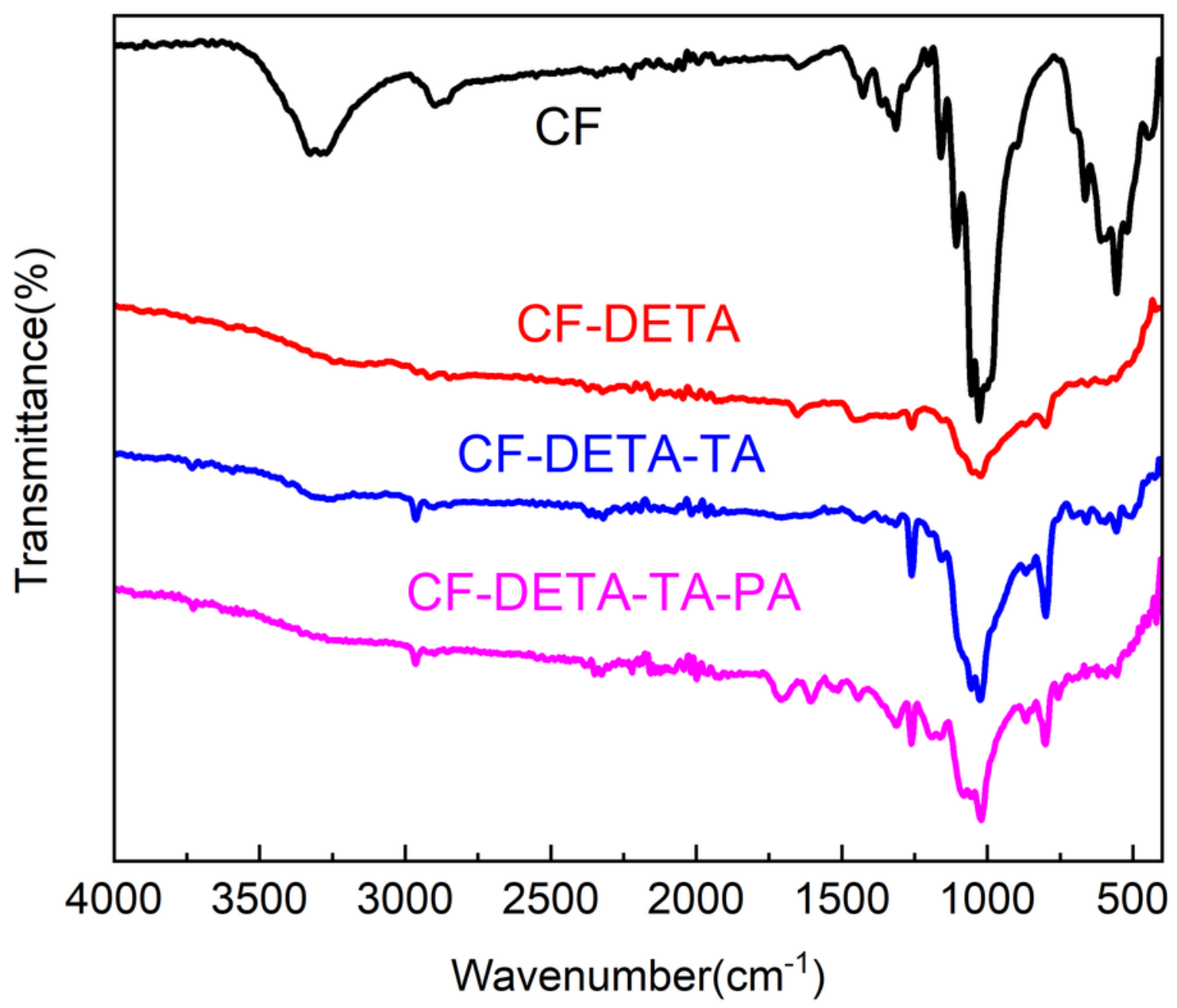

Figure 5

3.5 FTIR spectra of TA and TA-Cu
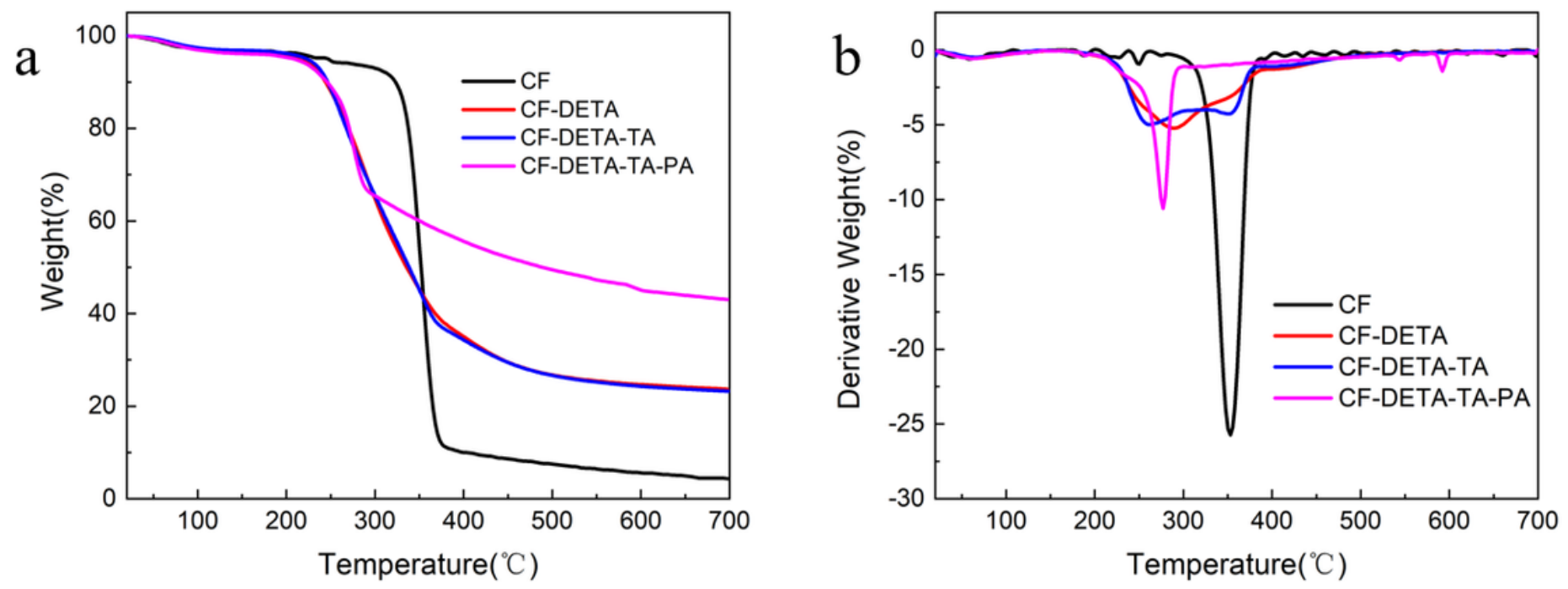
Figure 6

3.6 TG and DTG curves of control cotton and modified cotton fabric in nitrogen
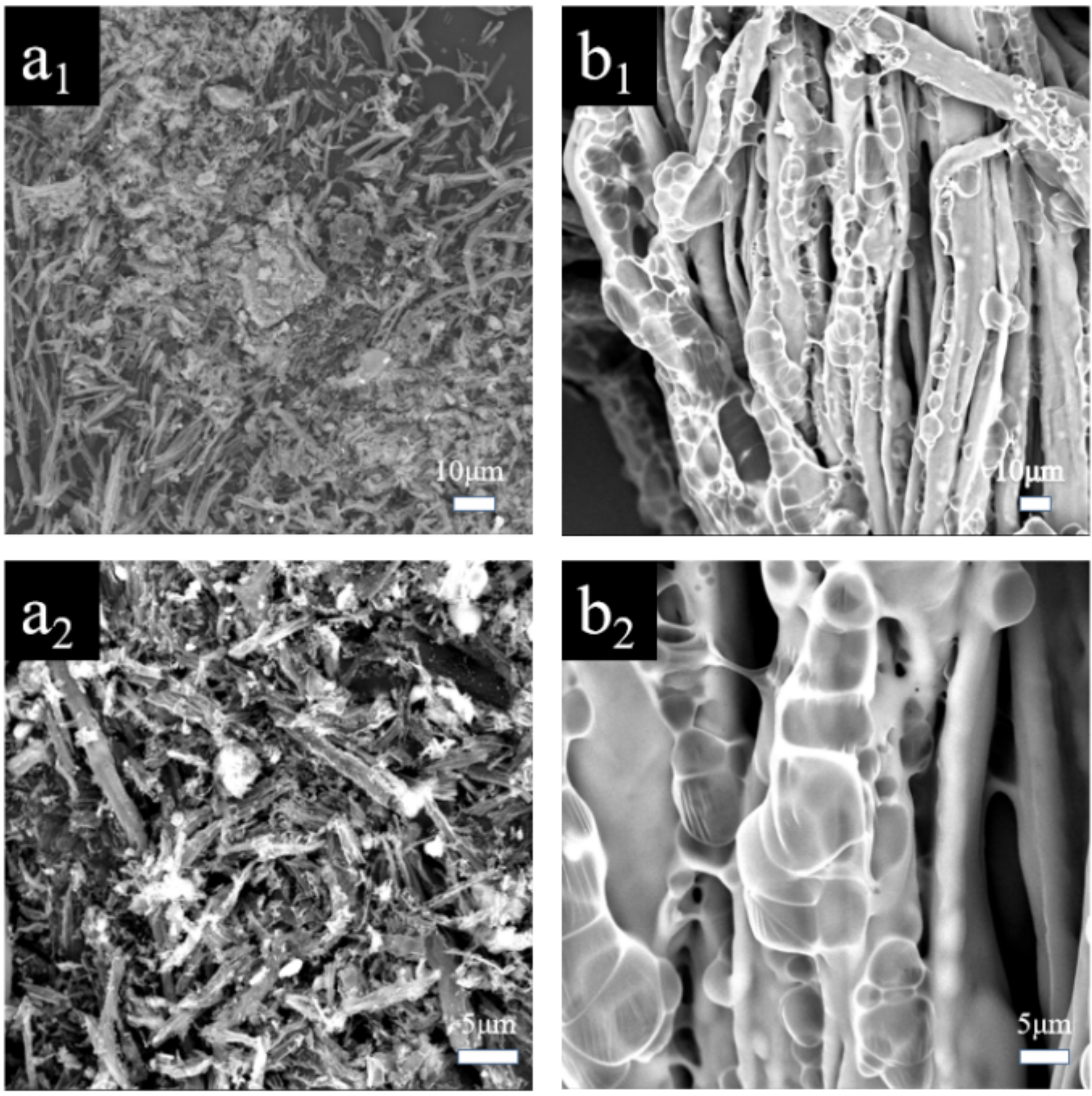

Figure 7

3.7 SEM image of $(\mathrm{a} 1, \mathrm{a} 2) \mathrm{CF}$ and $(\mathrm{b} 1, \mathrm{~b} 2)$ CF-DETA-TA-PA after burning 


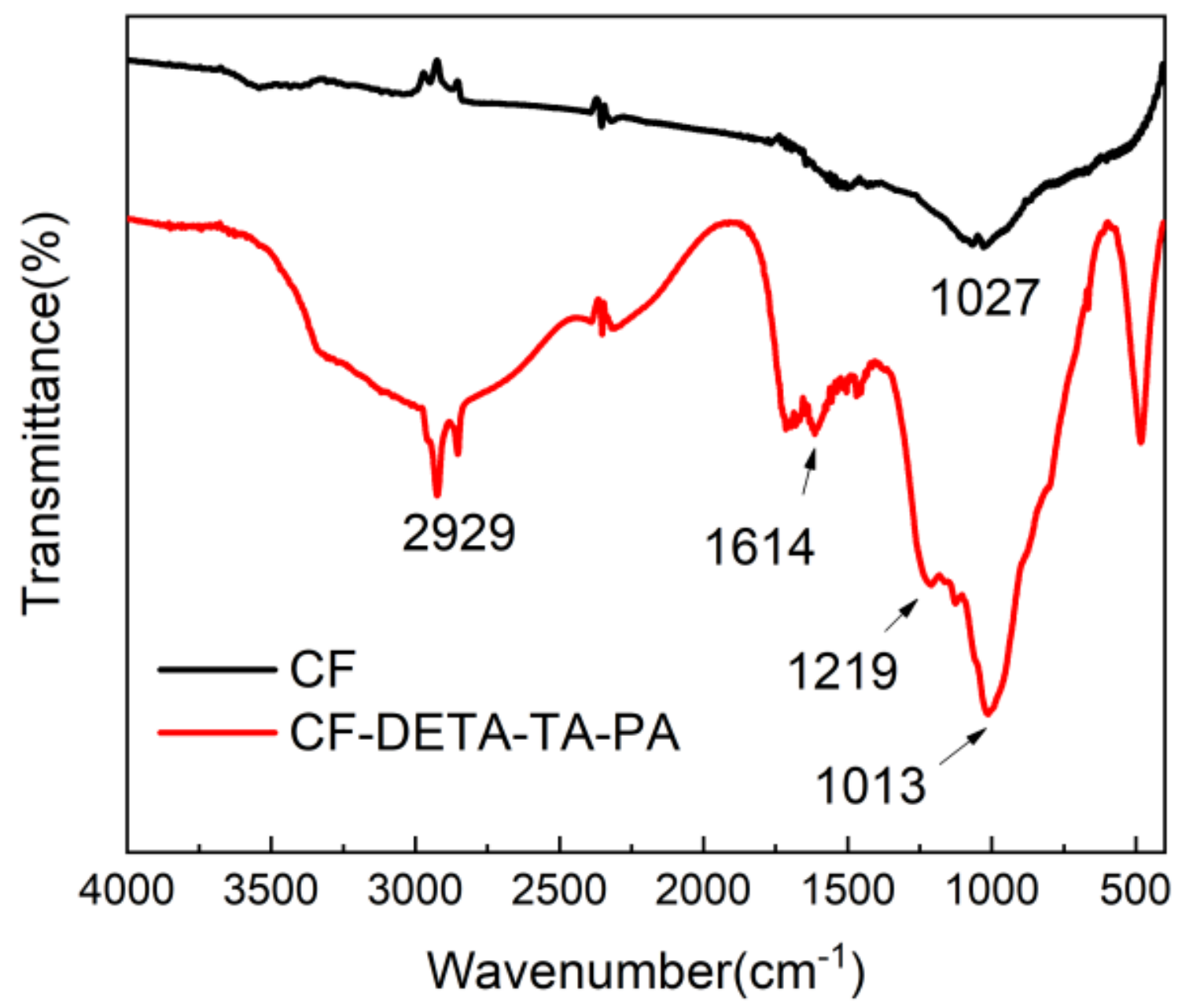

Figure 8

3.8 FTIR spectra of TA and TA-Cu after burning 


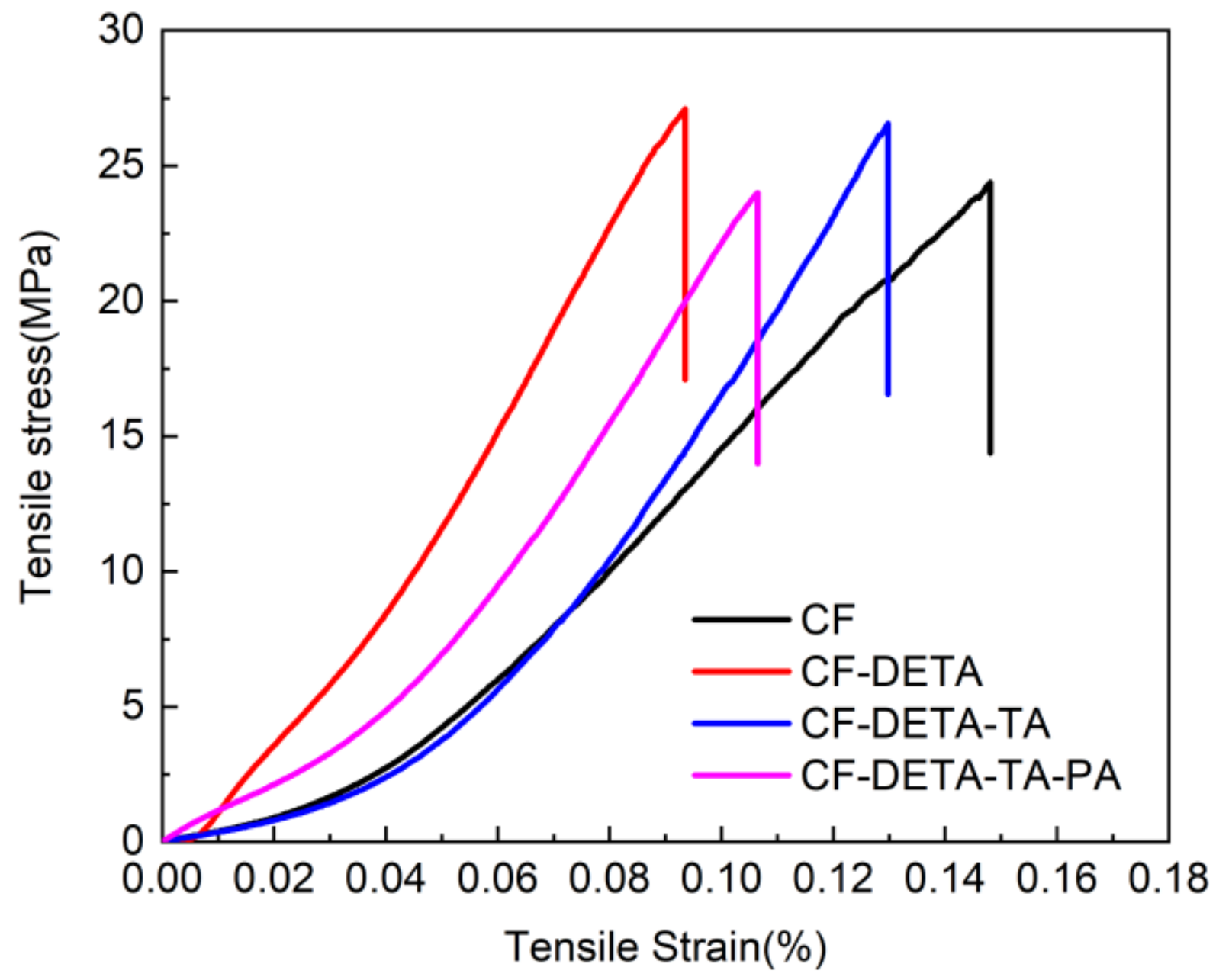

Figure 9

3.9 Strain-stress curves of control and treated samples 